\title{
Connecting cultures in the language classroom
}

\author{
Jonathan Newton \\ School of Linguistics and Applied Language Studies \\ Victoria University of Wellington
}

Reference: Newton, J. (2007). Connecting cultures in the language classroom. Polyglot 32 (Journal of the New Zealand Association of Language Teachers)

Intercultural language learning (IcLL) differs from approaches that focus on language without reference to culture, as well as approaches in which teaching about culture is secondary to teaching language or is treated as a largely autonomous strand alongside language. Instead, IcLL treats language and culture as inseparable. It focuses on raising awareness of culture in, around and through language as it is experienced in the lives of the students and people from the target language culture(s). The aim is to develop interculturally competent learners who can confidently navigate intercultural interactions and relationships.

One of the challenges in focusing on culture is that knowledge of one's own culture is largely implicit, and so not easily available for conscious reflection. We are often unaware of the cultural values which allow us to communicate within our own culture, let alone those that underpin behaviour in another culture with which we come in contact. This is captured in the metaphor of the cultural iceberg in which a large proportion of culturally shaped knowledge (behavioural expectations, expectations of appropriateness and politeness in verbal and nonverbal behaviour etc) lies below the surface of culture, and is mostly only subconsciously applied in our everyday interactions.

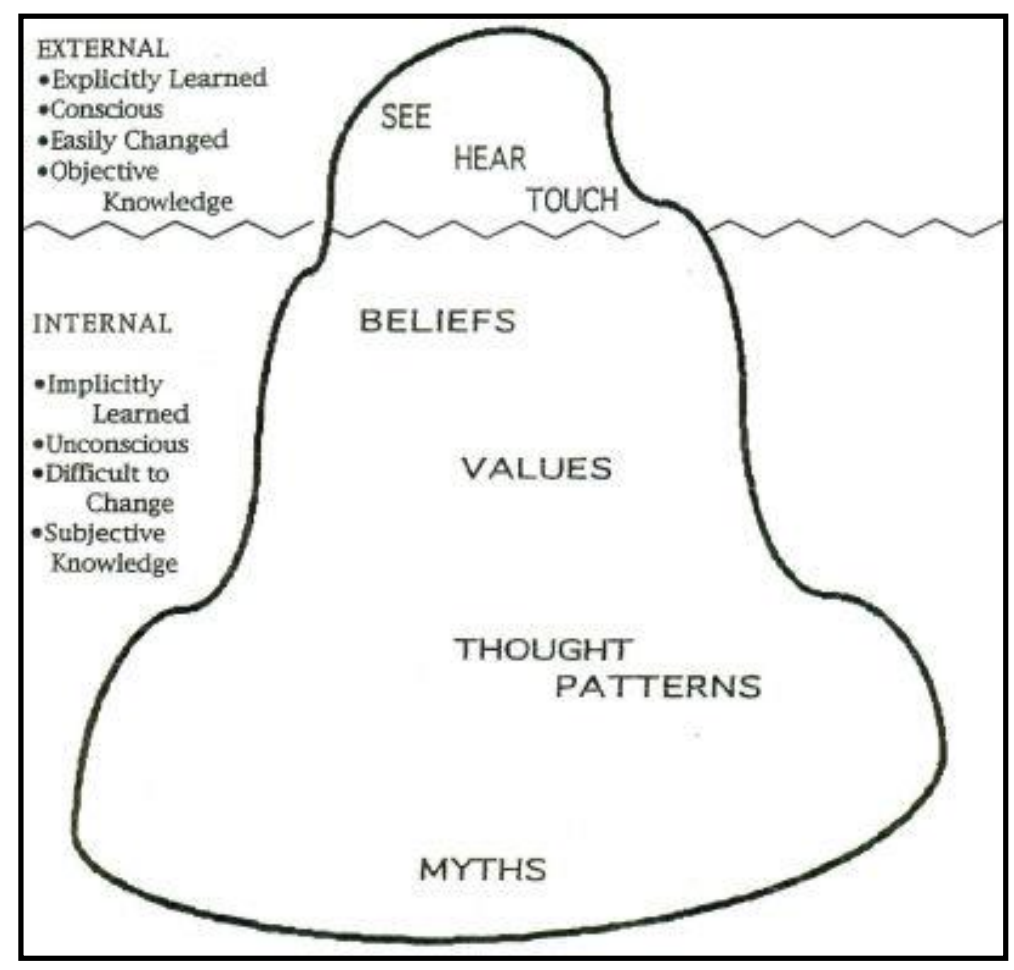

Figure 6: The Cultural Iceberg

(Weaver, 1993, sourced http://home.snu.edu/ hculbert/iceberg.htm) 
Greeting routines, for example, can be realized in various observable ways including a handshake, raised eyebrows, a kiss, or a nod of the head. However, lying beneath these behaviours are non-observable values, attitudes and expectations to do with status, relationships and social distance, all of which are uniquely structured and perceived within different cultural contexts. The iceberg model can also be applied to the language/culture relationship. Choice of linguistic form, just like behaviour choice, is shaped by 'hidden values, attributions and interpretations of the world' ((Finkbeiner and Koplin, 2002 pp.3-4). IcLL encourages learners to discover these less visible cultural dimensions of their own lives. This self-awareness of how their culture influences their language and behaviour choices is the foundation for being able to understand other cultures, and to make sense of and function sensitively in intercultural interactions. One of the aims of IcLL is therefore the development of cultural awareness, that is,

'a gradually developing inner sense of the equality of cultures, an increased understanding of your own and other people's cultures, and a positive interest in how cultures both connect and differ' (Tomlinson (2001) cited in Tomlinson and Matsuhara (2004 p.3)).

This notion was effectively expressed by Proust (cited in Phillips, 2002) when he wrote:

'The real voyage of discovery consists not in seeking new landscapes, but in having new eyes'.

Comparing languages and cultures is a useful way to draw learners' attention to the influence of invisible culture in their lives. In increasingly multicultural classrooms, these comparisons and connections can be multi-faceted, as learners explore and share each other's cultures, while cooperatively exploring the target culture and language. Tomlinson and Matsuhara (2004, p.4) suggest that teachers begin and end activities 'in the minds of the learners'. This can be done through such activities as encouraging them to think about an experience in their own culture, before providing them with a similar one in the target culture, or asking learners to "translate" a new experience in another culture into an equivalent experience in their own culture. Maintaining this kind of awareness of culture is a primary goal of intercultural language learning.

It is important to stress that comparison of a target culture with one's own culture is not an end in itself. Instead, it is a process which is designed to facilitate movement by the learner into what is referred to in the intercultural literature as 'a third place' (Kramsch 1993). This third place is an intercultural position between cultures, a position from which the learner can negotiate differences and interact comfortably across cultures. They do this by drawing on 'a reflective capacity to deal with cultural differences and to modify behaviour when needed' (Dellit, 2005, p.17). The goal of intercultural language teaching is therefore to facilitate this shift in the positioning of learners, so that they are no longer rooted only in the experiences and identity derived from their existing cultures and languages. Neither, however, do they reposition themselves within the target culture. As Kramsch (1993) describes it, 'the goal is not a balance of opposites, or a moderate pluralism of opinions but a paradoxical, irreducible confrontation that may change one in the process' (p.231). The changes referred to here as the learner enters a third place are personal and unique:

$[\mathrm{T}]$ the major task of language learners is to define for themselves what this 'third place' ... will look like ... Nobody, least of all the teacher, can tell them where that very personal place is; for each learner it will be differently located, and will make different sense at different times (Kramsch, 1993, p.257).

\section{Conclusions}


Comparing cultures is a practical focus for language teaching which allows learners to develop more sophisticated concepts of culture, and helps to undermine notions of the immutability of cultural values, and cross-cultural prejudices. Instruction focused on raising cultural awareness and making connections has the ultimate goal of producing what Byram (2006 p.4) calls 'intercultural speakers' - that is, people with the ability to communicate and interact across cultural boundaries.

\section{References}

Byram, M. (2006). Language teaching for intercultural citizenship. Keynote address. Paper presented at the NZALT Conference, University of Auckland.

Dellit, J. (2005). Getting Started with Intercultural Language Learning: A Resource for Schools. Melbourne: Asian Languages Professional Learning Project, Asia Education Foundation.

Finkbeiner, C., \& Koplin, C. (2002). A cooperative approach for facilitating intercultural communication [Electronic Version]. Reading online, 6. Retrieved 3 July 2007 from http://www.readingonline.org/newliteracies/finkbeiner/.

Kramsch, C. (1993). Context and Culture in Language Teaching. Oxford: Oxford University Press.

Phillips, J. K. (2003). National Standards for foreign language learning. In D. L. Lange \& R. M. Paige (Eds.), Perspectives on culture in Second language Learning (pp. 161-171). Greenwich, Connecticut: Information Age Publishing.

Tomlinson, B., \& Matsuhara, H. (2004). Developing cultural awareness: Integrating culture into a language course. MET, 13(1), 1-7.

\section{Acknowledgement}

This article is based on material included in a report on intercultural language learning commissioned by the New Zealand Ministry of Education in 2006. 